\title{
5-Fluorouracil may enrich cancer stem cells in canine mammary tumor cells in vitro
}

\author{
BIN ZHOU ${ }^{1}$, YIPENG JIN ${ }^{2}$, DI ZHANG ${ }^{2}$ and DEGUI LIN ${ }^{2}$ \\ ${ }^{1}$ College of Animal Science and Technology, Zhejiang A\&F University, Hangzhou, Zhejiang 311300; \\ ${ }^{2}$ The Clinical Department, College of Veterinary Medicine, China Agricultural University, \\ Haidian, Beijing 100193, P.R. China
}

Received October 2, 2016; Accepted October 24, 2017

DOI: $10.3892 / \mathrm{ol} .2018 .8267$

\begin{abstract}
Mammary gland carcinomas are the most common neoplasms in women and unsterilized female dogs. Owing to the existence of cancer stem cells (CSCs), chemotherapy is not able to cure these types of diseases completely. A number of studies have demonstrated that CSCs are resistant to chemotherapeutic drugs, but whether canine mammary tumor cells that have acquired resistance to 5-fluorouracil (5-FU) exhibited properties of CSCs remains unknown. The aim of the present study was to investigate whether 5-fluorouracil-resistant canine mammary tumor cells exhibited properties of CSCs. CSCs were analyzed using western blot assays, ultra-low attachment sphere cultures, flow cytometry and migration (wound healing and Transwell) assays. The results indicated that, compared with parental cells, proteins associated with the $\mathrm{Wnt} / \beta$-catenin signaling pathway and aldehyde dehydrogenase 1 were overexpressed, the number and size of spheres in the 5-FU-resistant cells were increased, the ratio of $\mathrm{CD} 44^{+} / \mathrm{CD} 24^{-/ \text {low }}$ cells was increased and the migratory ability was improved in vitro compared with the 5-FU-susceptible cells. In conclusion, stimulation with chemotherapeutic drugs including 5-FU is a good method for increasing the proportion of canine mammary tumor stem cells in vitro, which may provide further understanding of chemotherapeutic methods and CSCs.
\end{abstract}

\section{Introduction}

Mammary gland carcinomas are the most common neoplasms in women and unsterilized female dogs. The

Correspondence to: Professor Degui Lin, The Clinical Department, College of Veterinary Medicine, China Agricultural University, 2 Yuanmingyuan West Road, Haidian, Beijing 100193, P.R. China

E-mail: csamalin@163.com

Key words: 5-fluorouracil, drug resistance, canine mammary tumor cell, cancer stem cells, migration primary treatment of these types of disease in the clinic is through surgery; however, as the majority of the neoplasms are malignant, surgery is not always curative. In order to improve the quality and duration of life, chemotherapy is recommended to these patients. Unfortunately, chemotherapy may fail for a number of reasons, one of which is the existence of cancer stem cells (CSCs). CSCs are a subset of tumor cells with the ability to self-renew and generate the diverse types of cell that comprise a tumor $(1,2)$. The first solid malignancy from which CSCs were identified and isolated was breast cancer (2). A number of previous studies have revealed that CSCs are resistant to drugs, overexpress ATP-binding cassette transporters (3-5) and acquire invasive and metastatic properties through epithelial-mesenchymal transition (EMT) to avoid being killed (6). Through EMT, the transformed epithelial cells obtain mesenchymal traits that appear to contribute to migratory and invasive properties. EMT is considered the primary explanation of how tumor cells gain migratory and invasive properties in order to leave the primary tumor site, to disseminate throughout the body and eventually form distant metastases (7).

5-Fluorouracil (5-FU) and its derivatives are anti-metabolic drugs that are widely used in cancer chemotherapy. The effects of 5-FU have been attributed to the inhibition of thymidylate synthase (TS) and the incorporation of its metabolites into RNA and DNA (8). 5-FU has been used to treat various types of cancer and is used worldwide as a first-line anticancer drug for breast cancer chemotherapy $(9,10)$.

Dogs are a natural animal model for the study of human breast cancer $(11,12)$. A number of previous studies have suggested that CSCs are resistant to chemotherapeutic drugs, but whether cancer cells that have acquired resistance to drugs exhibited properties of CSCs remains unknown. The aim of the present study was to verify whether 5-FU stimulation may enrich CSCs in canine mammary tumor cells in vitro.

\section{Materials and methods}

Cell line. The canine mammary tumor CMT7364 cell line was obtained from a 13-year-old dog with a mammary tumor admitted to the China Agricultural University (Beijing, China) on November 2014, which was diagnosed 
as histological grade III intraductal papillary carcinoma according to a modified World Health Organization clinical staging system (13). At the time of publication, this cell line had already been propagated for $>100$ generations. Ethical approval for extraction of the mammary tumor cell line was provided by the China Agricultural University Laboratory Animal Welfare and Animal Experimental Ethical Committee (Beijing, China) and consent was provided by the dog's owner.

Cell culture. The 5-FU-resistant cell line was established from the CMT7364 cells through culturing with stepwise increasing concentrations of 5-FU (Hefei Bomei Biotechnology Co., Ltd., Anhui, China) in Dulbecco's modified Eagle's medium (DMEM) supplemented with $10 \%$ fetal bovine serum (FBS) (both from Gibco; Thermo Fisher Scientific, Inc., Waltham, MA, USA) and antibiotics (penicillin $100 \mathrm{IU} / \mathrm{ml}$ and streptomycin $100 \mathrm{IU} / \mathrm{ml}$; Gibco; Thermo Fisher Scientific, Inc.). The original concentration of 5 -FU was $10 \mathrm{ng} / \mathrm{ml}$, which was increased by $10 \mathrm{ng} / \mathrm{ml}$ at each interval (14 intervals total) until it reached $150 \mathrm{ng} / \mathrm{ml}$, as previously described (14). As the concentration of 5-FU increased, the cell proliferation rate decreased. The resistant cell line was continuously cultured for 8 months, and was termed CMT7364/5-FU.

Drug resistance assay. The sensitivity of CMT7364/5-FU cells (with CMT7364 cells as a control) to 5-FU was detected using the Cell Counting Kit-8 (CCK-8; Dojindo Molecular Technologies, Inc., Kumamoto, Japan) assay. Briefly, cells were treated with various concentrations (double dilution method from $0.5 \mathrm{mg} / \mathrm{ml}$ to $3.9625 \mu \mathrm{g} / \mathrm{ml}$ ) of 5 -FU for a period of $72 \mathrm{~h}$ at $37^{\circ} \mathrm{C}$. Following this, the culture medium (DMEM with 10\% FBS and antibiotics) was replaced with $90 \mu \mathrm{l}$ DMEM and $10 \mu \mathrm{l}$ CCK-8 for an additional $1.5 \mathrm{~h}$ of incubation in $37^{\circ} \mathrm{C}$. Then, the optical density (OD) values were measured at $450 \mathrm{~nm}$ on a microplate reader (ELx808 ${ }^{\mathrm{TM}}$; BioTek Instruments, Inc., Winooski, VT, USA). Different OD values represent a different number of viable cells, with higher OD values corresponding to higher viability levels. Then, the half-maximal inhibitory concentration $\left(\mathrm{IC}_{50}\right)$ values of CMT7364/5-FU cells and CMT7364 cells to 5-FU were calculated and compared.

Western blotting. Confluent cells were washed twice with ice-cold PBS and lysed on ice in radioimmunoprecipitation assay buffer containing a protease inhibitor cocktail (both from Beyotime Institute of Biotechnology, Haimen, China). Protein lysates were collected by centrifugation at $1,400 \mathrm{xg}$ at $4^{\circ} \mathrm{C}$ for $10 \mathrm{~min}$, and the total protein concentration was determined using a bicinchinonic acid protein assay kit (Beyotime Institute of Biotechnology). Subsequently, an equal amount of total protein $(40 \mu \mathrm{g} / \mathrm{lane})$ was loaded and separated by SDS-PAGE (10\% gel). Proteins were then transferred onto a polyvinylidene difluoride membrane (Sigma-Aldrich; Merck KGaA, Darmstadt, Germany), blocked with $5 \%$ non-fat dry milk (BD Biosciences, Franklin Lakes, NJ, USA) for non-specific binding at room temperature for $1 \mathrm{~h}$ and probed at $4^{\circ} \mathrm{C}$ overnight with primary antibodies against $\beta$-catenin (anti-mouse monoclonal; cat. no. sc-133240; 1:400 dilution), aldehyde dehydrogenase 1 (ALDH-1; anti-goat polyclonal; cat. no. sc-26713; 1:500 dilution) and prostaglandin-endoperoxide synthase 2 (COX-2; anti-goat polyclonal; cat. no. sc-1745; 1:400 dilution) (all from Santa Cruz Biotechnology, Inc., Dallas, TX, USA). The internal inference protein was GAPDH (anti-mouse monoclonal; cat. no. sc-16674; 1:500 dilution; Santa Cruz Biotechnology, Inc.). Following three 5-min washes with PBS containing $0.1 \%$ Tween-20 (PBST), blots were probed at room temperature for $1.5 \mathrm{~h}$ with secondary antibody in PBST [horseradish peroxidase (HRP)-conjugated donkey anti-mouse immunoglobulin $\mathrm{G}(\operatorname{IgG})$; cat. no. sc-2314; 1:2,000 dilution or HRP-conjugated rabbit anti-goat IgG; cat. no. sc-2768; 1:1,000 dilution; both from Santa Cruz Biotechnology, Inc.]. Following three 5-min washes with PBST, immunoreactivity was detected using an enhanced chemiluminescence advance western blot detection kit (Thermo Fisher Scientific, Inc.).

Sphere-forming assay. The sphere-forming assay was performed as previously described (13), with minor modifications. In brief, single cell suspensions were seeded on ultra-low attachment 6-well plates at a density of 10,000 viable cells/well. Cells were grown in serum-free DMEM/Ham's F12, supplemented with B27 (Invitrogen; Thermo Fisher Scientific, Inc.), $20 \mathrm{ng} / \mathrm{ml}$ epidermal growth factor and $20 \mathrm{ng} / \mathrm{ml}$ basic fibroblast growth factor (BD Biosciences) for 14 days. Mammospheres were counted under a light microscope (x40 and $\mathrm{x} 100)$. This experiment was performed three times.

Flow cytometric assay. CMT7364/5-FU and CMT7364 cells in the exponential growth phase were digested with trypsin and resuspended in PBS. Following centrifugation at $100 \mathrm{x} \mathrm{g}$ for $5 \mathrm{~min}$ at $4^{\circ} \mathrm{C}$, the cells were washed with loading buffer $(\mathrm{PBS}+2 \%$ FBS) twice. Phycoerythrin (PE)-conjugated cluster of differentiation 24 (CD24) (clone M1/69, mouse anti-human; cat. no. 553261; 1:800 dilution; BD Biosciences) and allophycocyanin (APC)-conjugated CD44 (clone IM7, mouse anti-human; cat. no. 561859; 1:800 dilution; BD Biosciences) antibodies were added to the cells. The cells containing the antibodies were cultured in the dark on ice for $45 \mathrm{~min}$. Following washing twice with loading buffer, $400 \mu 1$ loading buffer was used to resuspend the cell pellets. The samples were transferred into flow cytometry tubes and examined using a FACSCalibur flow cytometer (BD Biosciences); the proportions of $\mathrm{CD} 44^{+} / \mathrm{CD} 24^{- \text {/low }}$ cells were then compared using FlowJo software (version 10.0.7; FlowJo, LLC, Ashland, OR, USA). The experiment was performed three times.

Wound healing assay. A wound healing assay was performed to evaluate the migratory ability of cells. Cells $\left(5 \times 10^{5}\right)$ were seeded in a 6-well plate and grown to confluence (almost $90 \%$ ), and the monolayer cells were scratched with a $200 \mu \mathrm{l}$ pipette tip to create a $0.4-\mathrm{mm}$ wide wound. Plates were washed with PBS to remove floating cells and debris, and then the cells were incubated at $37^{\circ} \mathrm{C}$ for 24 or $48 \mathrm{~h}$ with DMEM without FBS. Three wells were used for each group, and images of cell migration were captured under a 
fluorescence microscope (CKX41; Olympus Corporation, Tokyo, Japan) at 0 and $48 \mathrm{~h}$, respectively. The relative open wound area (the open wound area of $48 \mathrm{~h} /$ the open wound area of $0 \mathrm{~h} \times 100 \%)$ was calculated using Image J software 1.46 (National Institutes of Health, Bethesda, MA, USA).

Migration assay (Transwell). Transwell filters (8- $\mu \mathrm{m}$ pore size; Costar; Corning Inc., Corning, NY, USA) were placed in 24-well plates, and then the CMT7364 and CMT7364/5-FU cells were seeded onto the filters at a concentration of 2,000 cells/well in $100 \mu 1 \mathrm{FBS}$-free DMEM. The lower chambers were filled with $600 \mu 1$ DMEM with $10 \%$ FBS. Three wells were used for each group. After $48 \mathrm{~h}$ at $37^{\circ} \mathrm{C}$, the cells on the top side of the filters were removed by a tipped swab. The number of cells that had migrated to the lower side of the filters was determined by $0.1 \%$ crystal violet staining at room temperature, and visualized under a light microscope at $\mathrm{x} 40$ magnification. The experiment was performed three times.

Statistical analysis. Results are presented as individual data or the mean \pm standard deviation. Unpaired Student's t-tests and two-way analysis of variance followed by Bonferonni's post hoc multiple comparisons of means were used to evaluate the differences between samples and the respective controls. $\mathrm{P}<0.05$ was considered to indicate a statistically significant difference, and $\mathrm{P}<0.01$ was considered to indicate a highly statistically significant difference. The data analyses were performed using GraphPad Prism (version 5; GraphPad Software, Inc., La Jolla, CA, USA).

\section{Results}

$I C_{50}$ values of different cells to $5-F U$. The $\mathrm{IC}_{50}$ values of 5-FU for CMT7364 cells and CMT7364/5-FU cells were $0.195 \pm 0.025$ and $2.54 \pm 0.15 \mu \mathrm{g} / \mathrm{ml}$, respectively. Results are presented in Fig. 1.

CSC-associated proteins are overexpressed. In order to investigate whether drug-resistant cells demonstrated the characteristics of CSCs, the expression of the Wnt/ $\beta$-catenin signaling pathway components COX- 2 and $\beta$-catenin, and CSC marker ALDH-1 were examined. GAPDH was used as an internal reference. The results indicated that all these target proteins were upregulated in CMT7364/5-FU cells (Fig. 2).

Identification of spheres derived from the two cell lines. To confirm the existence of CSCs, the ability of these two cell lines to form spheres was examined using an ultra-low attachment culture assay. The two cell lines formed free-floating spheres when cultured in serum-free culture medium supplemented with growth factors for 14 days. As presented in Fig. 3A and B, the numbers of spheres were $109 \pm 9.644$ and $85.333 \pm 10.263$ in CMT7364/5-FU cells and CMT7364 cells, respectively $(\mathrm{P}<0.05)$.

Identification of $\mathrm{CD} 44^{+} / \mathrm{CD} 24^{- \text {llow }}$ subpopulations in the two cell lines. The two cell lines were cultured in DMEM

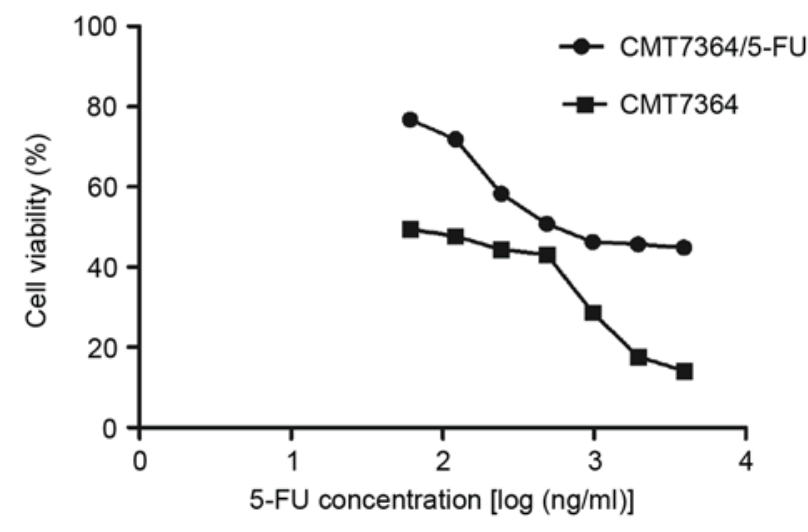

Figure 1. Cell viability at different concentrations of 5-FU. The difference between the half maximal inhibitory concentration values was highly statistically significant $(\mathrm{P}<0.01)$. 5-FU, 5-fluorouracil.

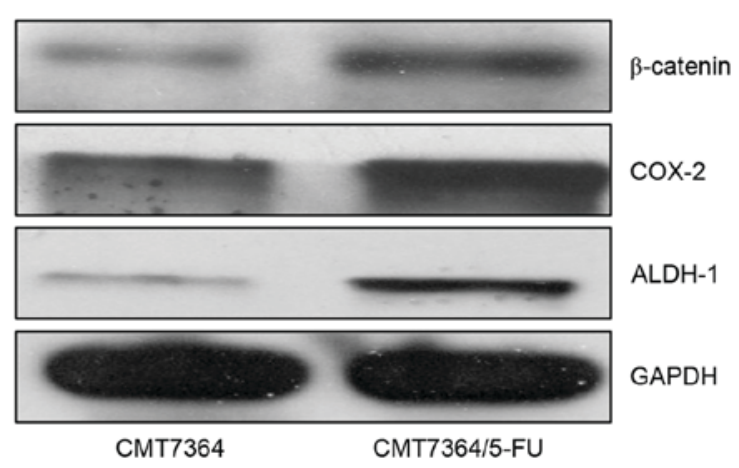

Figure 2. Western blot results of CSC-associated proteins. The Wnt/ $\beta$-catenin signaling pathway ( $\beta$-catenin and COX-2) and CSC surface markers (ALDH-1) were determined, using GAPDH as the internal reference. Compared with the CMT7364 cells, all these proteins were upregulated in the CMT7364/5-FU cells. CSC, cancer stem cell; ALDH-1, aldehyde dehydrogenase 1; COX-2, prostaglandin-endoperoxide synthase 2; 5-FU, 5-fluorouracil.

supplemented with 10\% FBS and antibiotics (penicillin $100 \mathrm{IU} / \mathrm{ml}$ and streptomycin $100 \mathrm{IU} / \mathrm{ml}$ ) at $37^{\circ} \mathrm{C}$ and analyzed using fluorescence-conjugated CD44 and CD24 antibodies and subjected to flow cytometry. In Fig. 3C, the $y$-axes were APC-CD44 and x-axes were PE-CD24. The $\mathrm{CD} 44^{+} / \mathrm{CD} 24^{-/ \text {low }}$ cells were in the second quadrant (upper left), and these cells were considered to be CSCs. The proportion of these cells in the whole cell population was $98.58 \pm 0.07 \%$ in CMT7364/5-FU cells and $95.91 \pm 0.10 \%$ in CMT7364 cells (Fig. 3D).

Migratory ability. In the wound healing assay, the number of cells that migrated into the wound area in the CMT7364/5-FU cells was significantly increased compared with the CMT7364 cells $(\mathrm{P}<0.01)$. After $48 \mathrm{~h}$, the relative open wound areas were $31.57 \pm 0.82 \%$ in the CMT7364/5-FU cells and $66.17 \pm 1.95 \%$ in the CMT7364 cells (Fig. 4A and B). The Transwell assay demonstrated a similar result. The number of cells that migrated to the lower filters in CMT7364/5-FU cells was $248.56 \pm 56.35$, but in the CMT7364 cells the number of cells was $66.89 \pm 11.35$ (Fig. 4C and D), with a statistically significant difference between them $(\mathrm{P}<0.01)$. 


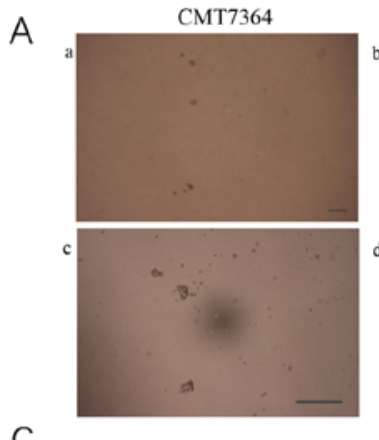

C

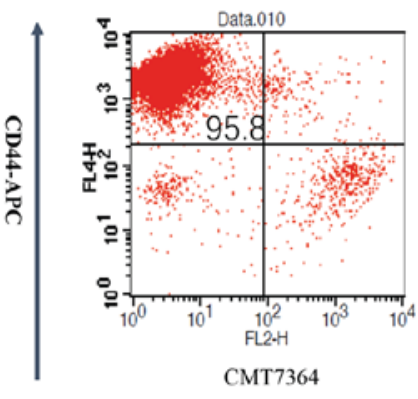

CMT7364/5-FU
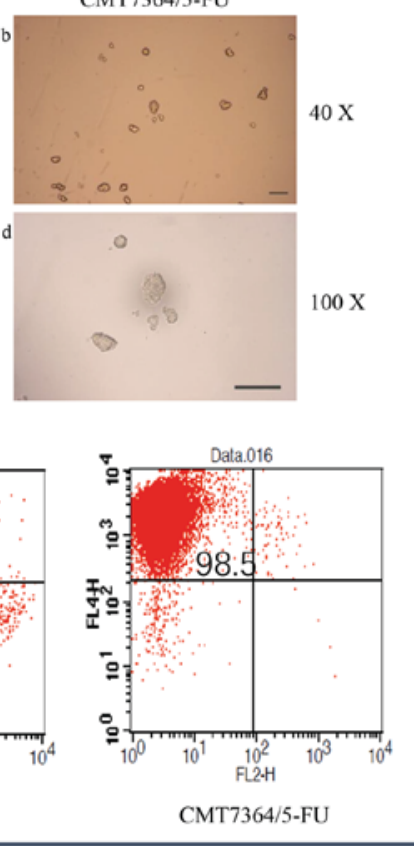

B

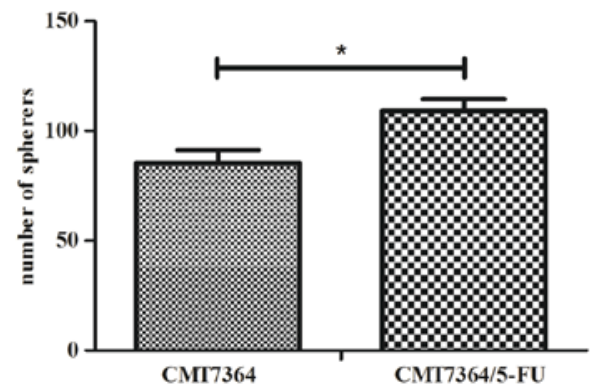

$\mathrm{D}$

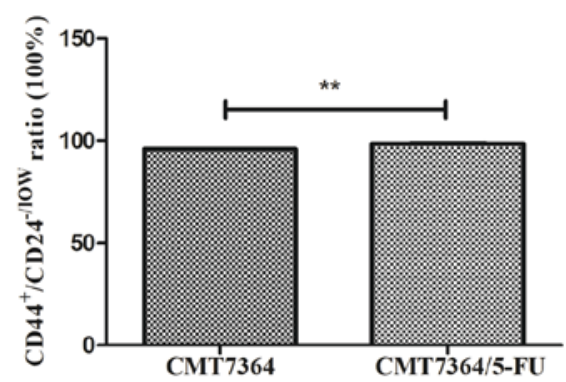

CD24-PE

Figure 3. Sphere-forming assay and flow cytometric assay. (A) Sphere-forming assay, compared with the CMT7364 cells, the number of spheres in the CMT7364/5-FU cells was increased and the average size of the spheres was larger. Scale bar, $50 \mu \mathrm{m}$. (B) The number of spheres in the CMT7364/5-FU cells and CMT7364 cells. The difference was statistically significant ( $\mathrm{P}=0.035)$. (C) Flow cytometric analysis of $\mathrm{CD} 44^{+} / \mathrm{CD} 24^{-/ / \mathrm{low}}$ subpopulation in the two types of cells The cells in Q2 correspond to CD44 $/ \mathrm{CD} 24^{- \text {/low }}$ cells. Results are presented as representative of three independent experiments. (D) Average CD44 $/ \mathrm{CD} 24^{-/ \mathrm{low}}$ ratio of cells in the different cell lines; the difference was highly statistically significant $\left({ }^{* *} \mathrm{P}<0.01\right)$. CD, cluster of differentiation; PE, phycoerythrin; 5-FU, 5-fluorouracil.

A

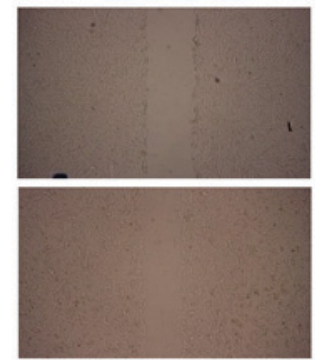

CMT7364

C

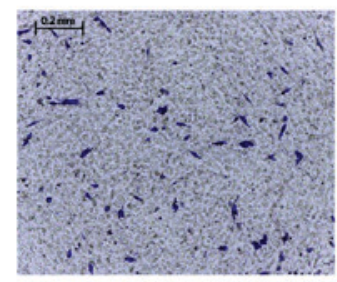

CMT7364

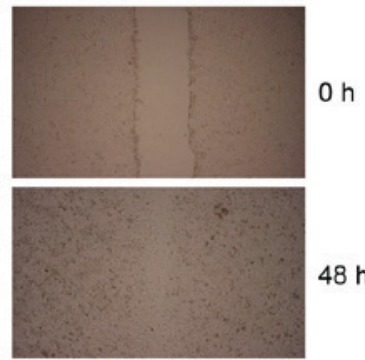

CMT7364/5-FU

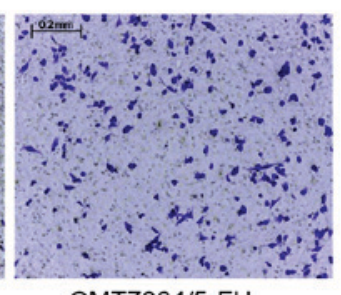

B

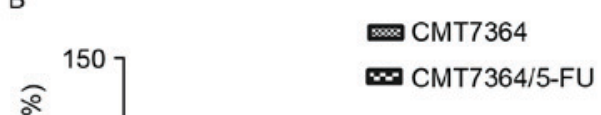

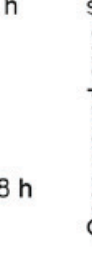

H

D

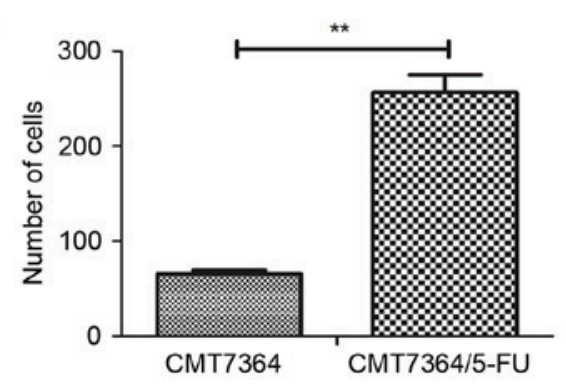

Figure 4. Wound healing assay and Transwell assay. (A) Confluent monolayers of cells following scratching with a $200 \mu l$ pipette tip at 0 and $48 \mathrm{~h}$ (x40 magnification). (B) The ratio of open wound area (the area of $48 \mathrm{~h} /$ the area of $0 \mathrm{~h} \mathrm{x} \mathrm{100 \% )} \mathrm{was} \mathrm{calculated} \mathrm{using} \mathrm{ImageJ} \mathrm{software;} \mathrm{the} \mathrm{difference} \mathrm{was} \mathrm{highly} \mathrm{statistically}$ significant ( $\left.{ }^{(* *} \mathrm{P}<0.01\right)$. Migratory ability was analyzed using a Transwell assay. (C) After $48 \mathrm{~h}$ treatment, cells that had passed through the Transwell into the lower wells were stained and counted (scale bar, $0.2 \mathrm{~mm}$ ). (D) The average number of cells that passed through the Transwell corresponding to the images in $(\mathrm{C})$; the difference was highly statistically significant $\left({ }^{* *} \mathrm{P}<0.01\right) .5$-FU, 5 -fluorouracil.

\section{Discussion}

Dogs are a natural animal model for the study of human breast cancer $(11,12)$, and canine mammary tumors are a common disease in China (15). Treatment for these types of disease may fail due to recurrence and metastasis, and these two events are associated with CSCs (16). It has been established that CSCs are resistant to chemotherapeutic drugs, but whether 
chemotherapeutic drug-resistant cancer cells exhibited properties of CSCs remains unknown. In the present study, whether canine mammary tumor cells that acquired resistance to 5-FU exhibited properties of CSCs was investigated. Currently, the optimal method of obtaining drug-resistant cells in vitro is chemotherapeutic drug stimulation. Low-concentration drug stimulation is a good method for stimulating the progress of resistance development in vitro. The first multidrug-resistant cell line was established in a rodent cell line in 1968 (17). A number of resistant human cancer cells have been established using this method, such as the adriamycin (ADR)-resistant breast cancer MCF-7/ADR cell line (18), the 5-FU-resistant colon cancer LoVo/5-FU cell line (19) and 5-FU-resistant breast cancer cells (20), but there have been few in canine cells. Over 8 months of culture, a 5-FU-resistant cell line was established to investigate whether these cells exhibited properties of CSCs.

The canonical Wnt/ $\beta$-catenin signaling pathway serves a crucial function in the proliferation, migration and self-renewal of CSCs (21). A previous study identified that this pathway is upregulated in human breast CSCs, and that the representative proteins of this pathway were $\beta$-catenin and COX-2 (22). ALDHs are important metabolic enzymes in CSCs, and their metabolic substrates retinoic acid, reactive oxygen species and reactive aldehydes directly and indirectly affect the various cellular processes in CSCs (23). ALDHs have been widely used to isolate and identify various CSCs and are regarded as consistent CSC markers (24). The results of the western blot analysis of the present study revealed that $\beta$-catenin, COX-2 and ALDH-1 were upregulated. This suggested that, in the 5 -FU-resistant cell line, the Wnt/ $\beta$-catenin signaling pathway was overactivated and ALDH-1 was increased.

CSCs reflect their 'stem-like' properties and abilities through sustaining tumorigenesis. Therefore, sphere formation is considered to be an additional characteristic of CSCs (25). In the sphere-forming assay in the present study, every sphere originated from a single CSC, and the sphere-forming efficiency of these two cell lines was analyzed. The sphere-forming rate of the CMT7364/5-FU cells was increased compared with the CMT7364 cells. This suggests that, in the CMT7364/5-FU cells, the proportion of CSCs was increased compared with that in the CMT7364 cells.

$\mathrm{CD} 44^{+} \mathrm{CD} 24^{-/ \text {low }}$ cells are considered to be CSCs in human breast cancer and canine mammary tumor $(26,27)$, as $\mathrm{CD} 44^{+} \mathrm{CD} 24^{- \text {llow }}$ cells are associated with enhanced invasiveness and increased tumorigenicity (the ability of small numbers of cells to form a tumor) compared with $\mathrm{CD} 44^{+} \mathrm{CD} 24^{+}$ cells (2). Using a flow cytometric assay, the proportions of CD $44^{+} \mathrm{CD} 24^{-/ \text {low }}$ cells in the CMT7364 and CMT7364/5-FU cells were examined. In the drug-resistant cells, the number of $\mathrm{CD} 44^{+} \mathrm{CD} 24^{-/ \text {low }}$ cells was increased compared with that in the CMT7364 cells.

One previous study demonstrated that CSCs exhibit an association with cell migration (28). One previous study considers EMT as an additional characteristic of CSCs, as cells may avoid being killed through migration to distant organs, consequently developing a new tumor (29). This is typified by the dissolution of cell-cell junctions and a loss of apico-basolateral polarity, resulting in the formation of migratory mesenchymal cells with invasive properties (30).
Mesenchymal tumor cells that have undergone EMT appear to share a variety of hallmark capabilities with experimentally defined CSCs (28). At present, the optimum method for investigating the properties of migration in vitro are wound healing and Transwell assays. In the present study, these two protocols demonstrated similar results, which was that 5-FU-resistant cells were much easier to migrate compared with 5-FU-susceptible cells in vitro.

In conclusion, 5-FU stimulation is a good method for obtaining drug-resistant cancer cells, and 5-FU stimulation may increase the proportion of canine mammary tumor stem cells in vitro; however, the precise underlying molecular mechanism remains unclear and requires additional investigation.

\section{Acknowledgements}

The present study was supported by the National Natural Science Foundation of China (grant no. 31372489).

\section{References}

1. Reya T, Morrison SJ, Clarke MF and Weissman IL: Stem cells, cancer, and cancer stem cells. Nature 414: 105-111, 2001.

2. Al-Hajj M, Wicha MS, Benito-Hernandez A, Morrison SJ and Clarke MF: Prospective identification of tumorigenic breast cancer cells. Proc Natl Acad Sci USA 100: 3983-3988, 2003.

3. Dean M, Fojo T and Bates S: Tumour stem cells and drug resistance. Nat Rev Cancer 5: 275-284, 2005.

4. Dean M: ABC transporters, drug resistance, and cancer stem cells. J Mammary Gland Biol Neoplasia 14: 3-9, 2009.

5. Lage H: An overview of cancer multidrug resistance: A still unsolved problem. Cell Mol Life Sci 65: 3145-3167, 2008.

6. Huang J, Li H and Ren G: Epithelial-mesenchymal transition and drug resistance in breast cancer (Review). Int J Oncol 47: 840-848, 2015.

7. Bill R and Christofori G: The relevance of EMT in breast cancer metastasis: Correlation or causality? FEBS Lett 589: 1577-1587, 2015.

8. Oguri T, Bessho Y, Achiwa H, Ozasa H, Maeno K, Maeda H, Sato $\mathrm{S}$ and Ueda R: MRP8/ABCC11 directly confers resistance to 5-fluorouracil. Mol Cancer Ther 6: 122-127, 2007.

9. Longley DB, Harkin DP and Johnston PG: 5-Fluorouracil: Mechanisms of action and clinical strategies. Nat Rev Cancer 3: 330-338, 2003

10. Karayannopoulou M, Kaldrymidou E, Constantinidis TC and Dessiris A: Adjuvant post-operative chemotherapy in bitches with mammary cancer. J Vet Med A Physiol Pathol Clin Med 48: 85-96, 2001.

11. Rasotto R, Goldschmidt MH, Castagnaro M, Carnier P, Caliari D and Zappulli V: The dog as a natural animal model for study of the mammary myoepithelial basal cell lineage and its role in mammary carcinogenesis. J Comp Pathol 151: 166-180, 2014.

12. Uva P, Aurisicchio L, Watters J, Loboda A, Kulkarni A, Castle J, Palombo F, Viti V, Mesiti G, Zappulli V, et al: Comparative expression pathway analysis of human and canine mammary tumors. BMC Genomics 10: 135, 2009.

13. Goldschmidt M, Peña L, Rasotto R and Zappulli V: Classification and grading of canine mammary tumors. Vet Pathol 48: 117-131, 2011.

14. Zhou B, Zhang D, Pei SM, Zhang H, Du HC, Jin YP and Lin DG: Establishment of 5-fluorouracil-resistant canine mammary tumor cell line. Pol J Vet Sci 20: 103-110, 2017.

15. Moe L: Population-based incidence of mammary tumours in some dog breeds. J Reprod Fertil Suppl 57: 439-443, 2001.

16. Bohl CR, Harihar S, Denning WL, Sharma R and Welch DR: Metastasis suppressors in breast cancers: Mechanistic insights and clinical potential. J Mol Med (Berl) 92: 13-30, 2014.

17. Kessel D, Botteril V and Wodinsky I: Uptake and retention of daunomycin by mouse leukemic cells as factors in drug response. Cancer Res 28: 938-941, 1968. 
18. Tran TP, Kim HG, Choi JH, Na MK and Jeong HG: Reversal of P-glycoprotein-mediated multidrug resistance is induced by mollugin in MCF-7/adriamycin cells. Phytomedicine 20 622-631, 2013

19. Wang T, Chen Z, Zhu Y, Pan Q, Liu Y, Qi X, Jin L, Jin J, Ma X and Hua D: Inhibition of transient receptor potential channel 5 reverses 5-fluorouracil resistance in human colorectal cancer cells. J Biol Chem 290: 448-456, 2015.

20. Takahashi K, Tanaka M, Inagaki A, Wanibuchi H, Izumi Y, Miura K, Nagayama K, Shiota M and Iwao H: Establishment of a 5-fluorouracil-resistant triple-negative breast cancer cell line. Int J Oncol 43: 1985-1991, 2013.

21. Curtin JC and Lorenzi MV: Drug discovery approaches to target Wnt signaling in cancer stem cells. Oncotarget 1: 552-566, 2010.

22. Zhao Z, Lu P, Zhang H, Xu H, Gao N, Li M and Liu C: Nestin positively regulates the $\mathrm{Wnt} / \beta$-catenin pathway and the proliferation, survival, and invasiveness of breast cancer stem cells. Breast Cancer Research 16: 408, 2014.

23. Douville J, Beaulieu R and Balicki D: ALDH1 as a functional marker of cancer stem and progenitor cells. Stem Cells Dev 18 17-25, 2009.
24. Xu X, Chai S, Wang P, Zhang C, Yang Y, Yang Y and Wang K: Aldehyde dehydrogenases and cancer stem cells. Cancer Lett 369: 50-57, 2015.

25. Yin $\mathrm{Y}, \mathrm{Li} \mathrm{C}, \mathrm{Yu} \mathrm{A}$ and Wang X: Enrichment of breast cancer stem cells by serum-free culture. Chin J Clin Exp Pathol 31: 966-970, 2015.

26. Bozorgi A, Khazaei M and Khazaei MR: New findings on breast cancer stem cells: A review. J Breast Cancer 18: 303-312, 2015.

27. Camerlingo R, Ferraro GA, De Francesco F, Romano M, Nicoletti G, Di Bonito M, Rinaldo M, D'Andrea F and Pirozzi G: The role of CD $44^{+} / \mathrm{CD} 24^{-/ \mathrm{low}}$ biomarker for screening, diagnosis and monitoring of breast cancer. Oncol Rep 31: 1127-1132, 2014

28. Scheel C and Weinberg RA: Cancer stem cells and epithelial-mesenchymal transition: Concepts and molecular links. Semin Cancer Biol 22: 396-403, 2012.

29. Biddle A and Mackenzie IC: Cancer stem cells and EMT in carcinoma. Cancer Metastasis Rev: Feb 3, 2012. (Epub ahead of print).

30. Singh A and Settleman J: EMT, cancer stem cells and drug resistance: An emerging axis of evil in the war on cancer. Oncogene 29: 4741-4751, 2010. 